\title{
Pengembangan Strategi Pembelajaran Menyenangkan "Permainan Bisik Berantai" Pada Pembelajaran Bahasa Inggris Kelas II di SD Mardi Yuana
}

\author{
Mariliana Berlian Bulo, ${ }^{\circledR}$ Suprayekti $^{2}$, Retno Widyaningrum ${ }^{3}$ \\ ${ }^{1}$ Universitas Negeri Jakarta, Jakarta, Indonesia. \\ ${ }^{2}$ Universitas Negeri Jakarta, Jakarta, Indonesia. \\ 3 Universitas Negeri Jakarta, Jakarta, Indonesia. \\ DOI: https://doi.org/10.21009/JPI.031.11
}

\begin{abstract}
Article History Abstrak
Received : 2020

Accepted : 2020

Published : 2020

Penelitian pengembangan ini bertujuan untuk menghasilkan strategi pembelajaran menyenangkan "permainan bisik berantai" untuk materi animals kelas II SD yang didalamnya terdapat komponen strategi pembelajaran yaitu urutan kegiatan pembelajaran, metode, media, evaluasi, dan waktu. Penelitian pengembangan ini dilakukan dengan mengikuti prosedur model

Keywords pengembangan ADDIE, terdiri dari lima tahap yaitu (1) Analysis: melakukan analisis tujuan pembelajaran dan karakteristik peserta didik, (2) Design: merencanakan dan merancang

Development, Learning Strategy,

Fun Learning, Whisper Race Game komponen-komponen strategi pembelajaran, (3) Development: mengembangkan strategi pembelajaran yang menyenangkan "permainan bisik berantai" dengan slide powerpoint untuk mata pelajaran Bahasa Inggris, (4) Implementation: melakukan ujicoba kepada para ahli, (5) Evaluation: mengevaluasi hasil pengembangan produk kepada Guru Bahasa Inggris Sekolah Dasar untuk mengetahui tingkat kelayakan strategi pembelajaran tersebut. Penelitian pengembangan ini telah melalui pengimplementasian yang dilakukan oleh para ahli (expert review) dan evaluasi yang mengambil responden yaitu Guru Bahasa Inggris Sekolah Dasar Mardi Yuana. Dari hasil implementasi yang diujicobakan kepada para ahli diperoleh nilai untuk materi sebesar 77\% (Baik), desain pembelajaran 72\% (Baik), dan media sebesar 2,68 (Baik). Sedangkan hasil dari evaluasi ujicoba one to one diperoleh hasil yaitu setiap komponen yang dikembangkan sudah sesuai dan mudah untuk dipahami. Hasil penelitian pengembangan ini menunjukkan bahwa strategi pembelajaran dapat digunakan untuk memfasilitasi siswa dalam proses pembelajaran.
\end{abstract}

\begin{abstract}
This development research aims to produce a fun learning strategy "whisper race game" for Elementary grade II animals materials in which there are learning strategy components that are sequences of learning activities, methods, media, evaluation, and time. This development research is done by following the ADDIE development model procedures, consisting of five stages namely (1) Analysis: Analyze the purpose of learning and characteristics of learners, (2) Design: Planning and designing the components of learning strategy, (3) Development: Develop a fun learning strategy "whisper race game" with powerpoint slides for english subjects, (4) Implementation: Testing Expert, (5) Evaluation: Evaluate the result of the product development for the english teacher elementary school to determine the level feasibility of the learning strategy. This development research has been implemented by the implementation of experts (expert review) and evaluation that took the respondents is english teacher in Mardi Yuana elementary school. From the results of the implementation that was tested by the experts obtained a value for the material is $77 \%$ (good), learning design is $72 \%$ (good), and media is 2,68 (good). The results of this development research indicate that learning strategy can be used to facilitate students in the learning process.
\end{abstract}

\footnotetext{
Corresponding author : Mariliana Berlian

Adress: Universitas Negeri Jakarta

Jakata, Indonesia

E-mail: mariliana.berlian@yahoo.com
}

(C) 2020 Universitas Negeri Jakarta 


\section{PENDAHULUAN}

Perkembangan dewasa ini telah menempatkan Bahasa Inggris sebagai bahasa yang digunakan dalam komunikasi internasional. Dalam posisinya, Bahasa Inggris merupakan bahasa ilmu pengetahuan dan teknologi, karena nya tanpa kemampuan Bahasa Inggris, seseorang akan mengalami kesulitan dalam komunikasi dengan dunia yang semakin terbuka, cepat, dan tak terkendali.

Kemampuan berbahasa Inggris sangat penting untuk dikenalkan kepada anak sedini mungkin. Sejumlah sekolah dasar juga telah menetapkan Bahasa Inggris sebagai muatan lokal. Muatan lokal merupakan bahan kajian yang dimaksudkan untuk membentuk pemahaman siswa terhadap potensi di daerah tempat tinggalnya, keputusan dalam memasukkan mata pelajaran Bahasa Inggris tersebut dilihat dari kebutuhan siswa dan ketersediaan guru pada masing-masing sekolah dasar.

Pada zaman yang serba digital sekarang ini semua sistem kehidupan sudah menggunakan Bahasa Inggris, dengan adanya Bahasa Inggris pada sekolah dasar akan lebih mempermudah untuk menerima teknologi yang digunakan. Kemudian dengan diberikannya Bahasa Inggris pada sekolah dasar otomatis ketika anak-anak akan melanjutkan pada jenjang selanjutnya, anak akan mudah menerima Bahasa Inggris.

Berdasarkan wawancara dengan $\mathrm{Bu}$ Clara Riwi Hatmi sebagai guru mata pelajaran Bahasa Inggris di SD Mardi Yuana mengenai pembelajaran Bahasa Inggris yang diadakan pada jenjang kelas rendah yaitu kelas II SD. Berdasarkan hasil wawancara observasi awal, diketahui bahwa Bahasa Inggris adalah mata pelajaran muatan lokal yang diselenggarakan mulai dari kelas satu sampai kelas enam, alokasi waktu pembelajaran khususnya pada kelas II yaitu dua jam pembelajaran atau 2×30 menit dalam satu minggu. Dalam usia sekolah dasar sangat penting untuk menciptakan suasana yang berbeda, siswa dapat memperoleh hal yang menyenangkan hatinya untuk belajar. Hal tersebut dapat memengaruhi kondisi otak siswa untuk menyerap informasi yang disampaikan secara maksimal dan meningkatkan konsentrasi siswa agar tidak terpengaruh dari gangguan luar kelas. Pembelajaran yang menyenangkan juga dapat menarik dan membuat siswa termotivasi dalam belajar.

Menurut Rudi Hartono pembelajaran yang menyenangkan akan selalu menggugah rasa ingin tahu siswa terhadap sesuatu. Rasa ingin tahu tersebut yang akan membuat siswa aktif dan merasakan ilmu yang mereka dapatkan akan bermanfaat. Rudi Hartono juga berpendapat bahwa apabila pembelajaran dikondisikan dalam suasana yang menyenangkan maka siswa akan kreatif dan inovatif.. Hal tersebut juga dapat berkaitan langsung dengan prestasi belajar siswa dengan nilai kognitif, kreativitas merupakan tahapan yang paling penting dalam pembelajaran.

Berdasarkan permasalahan yang terjadi dalam pembelajaran Bahasa Inggris kelas II SD, diperlukan sebuah strategi yang diharapkan dapat meningkatkan kemampuan menyimak dalam belajar bahasa. Pada hal tersebut, dibutuhkan sebuah kegiatan seperti permainan yang juga bisa dijadikan sebagai salah satu strategi untuk membuat suasana dalam proses pengajaran berjalan secara menyenangkan bagi para siswa, agar mudah menyerap bahasa yang diterima. Strategi yang dapat digunakan adalah strategi pembelajaran menyenangkan, strategi tersebut berusaha menciptakan suasana yang menyenangkan dan menghilangkan kejemuan siswa dalam menjalankan kegiatan belajarnya seharihari.

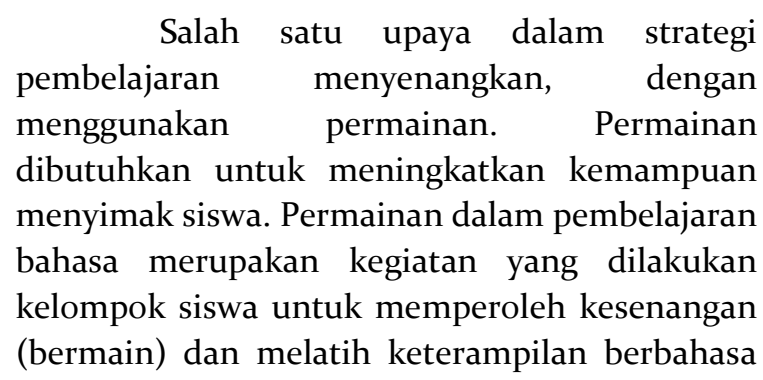


dengan mengikuti aturan-aturan tertentu, sehingga seorang atau kelompok dapat menjadi pemenang. Permainan bisik berantai adalah permainan yang dapat mengembangkan keterampilan kebahasaan, antara lain keterampilan menyimak dan berbicara. Permainan bisik berantai juga dapat dipergunakan dalam pembelajaran, karena sesuai dengan tingkat perkembangan siswa sekolah dasar yang masih cenderung senang bermain dan membangun kemampuan siswa dalam menyusun pikirannya.

Permainan bisik berantai dilakukan siswa dengan membisikkan pesan kepada temannya, kemudian teman yang terakhir melafalkan kembali pesan yang telah disimaknya dengan benar dan tepat, hal tersebut membangun kognitif siswa, dan juga nilai afektif siswa dari rasa tanggung jawab terhadap diri sendiri dan teman.

Berdasarkan pernyataan di atas, peneliti tertarik untuk mengembangkan strategi pembelajaran menyenangkan "permainan bisik berantai" pada pembelajaran Bahasa Inggris kelas II di SD Mardi Yuana. Pengembangan strategi ini diharapkan mampu mengatasi hambatanhambatan yang terjadi pada pelajaran Bahasa Inggris

\section{METODE}

Pengembangan strategi pembelajaran ini termasuk ke dalam metode peneliatan pengembangan (Reasearch and Development), yaitu metode penelitian yang digunakan untuk menghasilkan produk tertentu, dan menguji keefektifan produk tersebut (Sugiyono: 2010)

Alat pengumpulan data yang digunakan yaitu kuesioner dengan responden terdiri dari ahli materi, ahli desain pembelajaran, ahli media dan dua Guru Bahasa Inggris. Dalam ahli materi dan desain pembelajaran untuk melihat indikator dari aspek materi dan desain menggunakan skala guttman Ya dan Tidak dengan perhitungan skor $\mathrm{Ya}=1$ dan Tidak = o, kemudian pada ahli media mengacu pada penilaian skala dengan 4 jawaban. Skor yang telah diperoleh untuk menentukan kualitas media tersebut. merupakan data kuantitatif yang kemudian ditafsirkan menjadi data kualitatif dengan mengacu pada skala likert dengan kategori, sebagai berikut:

Tabel 1 Kategori Nilai

\begin{tabular}{ll}
\hline Keterangan & Keterangan \\
\hline $3,26-4,00$ & Sangat Baik \\
$2,5^{1}-3,25$ & Baik \\
$1,76-2,50$ & Cukup Baik \\
$1,00-1,75$ & Kurang Baik \\
\hline
\end{tabular}

\section{HASIL DAN PEMBAHASAN}

Berdasarkan analisis masalah yang ada, penelitian ini bertujuan untuk mengembangkan strategi pembelajaran. Berikut ini kajian teori yang dilakukan:

Model Pengembangan yang digunakan dalam pengembangan ini yaitu ADDIE. Model ADDIE yang terdiri dari Analysis, Design, Development, Implementation, Evaluation merupakan salah satu model desain pembelajaran yang memperlihatkan tahapantahapan dasar desain sistem pembelajaran

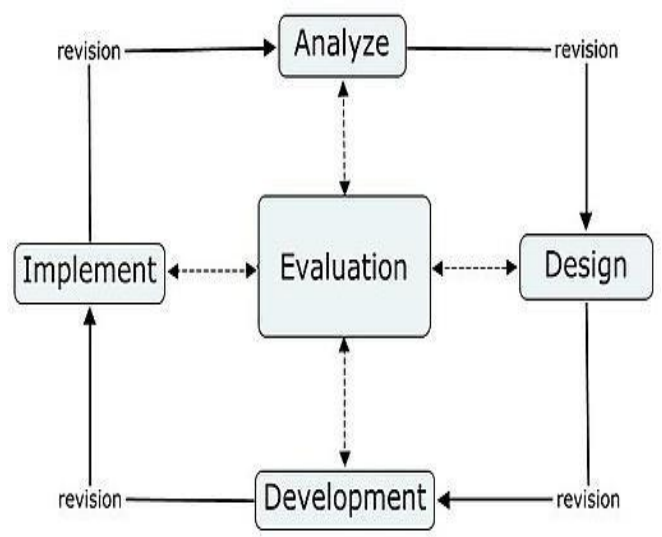

Tujuan pengembangan dari setiap tahapan berdasarkan model ADDIE, yakni sebagai berikut:

1. Mengetahui kebutuhan mata pelajaran Bahasa Inggris, berupa tujuan pembelajaran dan karakteristik peserta didik.

2. Merancang desain pembelajaran dan menentukan evaluasi yang akan digunakan untuk strategi 
pembelajaran yang menyenangkan "permainan bisik berantai".

3. Mengembangkan strategi pembelajaran yang menyenangkan "permainan bisik berantai" dengan slideshow powerpoint untuk mata pelajaran Bahasa Inggris.

4. Mengimplementasikan strategi pembelajaran yang menyenangkan "permainan bisik berantai" kepada para ahli.

5. Melakukan evaluasi strategi pembelajaran yang menyenangkan "permainan bisik berantai" kepada guru kelas II SD untuk mengetahui tingkat kelayakan strategi pembelajaran tersebut.

Pengembangan rancangan pelaksanaan pembelajaran Bahasa Inggris dengan strategi pembelajaran yang menyenangkan "permainan bisik berantai" dikembangkan dengan metode penelitian dan pengembangan (Research and Development). Metode penelitian dan pengembangan merupakan suatu metode penelitian yang digunakan untuk menghasilkan produk tertentu, dan menguji keefektifan produk tersebut.2 Model desain pembelajaran yang akan digunakan dalam pengembangan ini adalah model ADDIE. Adapun prosedur yang terdapat dalam model pengembangan ADDIE yang digunakan pada peneliti ini adalah:

Langkah 1: Analisis, pada langkah pertama ini pengembang menganalisis tujuan pembelajaran yang menghasilkan tujuan pembelajaran umum dan khusus, serta menganalisis karakteristik peserta didik yang akan menggunakan strategi tersebut.

Langkah 2: Design, pada langkah kedua ini pengembang merencanakan dan merancang komponen-komponen strategi pembelajaran yang meliputi urutan pembelajaran, kegiatan pembelajaran, metode, media, evaluasi, dan waktu.

Langkah 3: Development, pada tahap ketiga yaitu pengembang melakukan pengembangan strategi pembelajaran menjadi produk cetak yang telah disesuaikan dengan tahap desain.

Langkah 4: Implementasi, pada tahap keempat yaitu mengimplementasikan produk strategi pembelajaran dengan cara melakukan uji coba ahli materi, ahli desain pembelajaran, dan ahli media.

Cara yang dibutuhkan untuk ahli materi dan desain yaitu Perhitungan skor $\mathrm{Ya}=1$ dan Tidak $=$ o. Rumusnya sebagai berikut:

\[ P=\frac{f \times 100 \%}{n} \]
Keterangan:
$\mathrm{P}=$ Prosentase
$\mathrm{f}=$ Frekuensi dari setiap jawaban
$\mathrm{n}=$ Jumlah item
$100=$ Konstanta

Dengan kriteria hasil skor rata-rata sebagai berikut:

o\% - 50\% : Sangat Baik

$51 \%-100 \%$ : Baik

Sedangkan untuk ahli media yaitu menghitung kuesioner berdasarkan skala penilaian yang telah ditentukan (skala 1-4). Skor rata-rata nilai dari keseluruhan aspek akan dikategorikan kedalam kriteria dengan skala likert:

Tabel 2 Skala likert

\begin{tabular}{cc}
\hline Skala & Nilai \\
\hline $\begin{array}{c}\text { Kurang } \\
\text { Baik }\end{array}$ & 1 \\
Cukup & 2 \\
Baik & 3 \\
Sangat & 4 \\
Baik & \\
\hline
\end{tabular}


Hasil data yang diperoleh menggunakan kuesioner diolah dengan statistika sederhana, dengan sebagai berikut:

Skor rata-rata $=$ Jumlah keseluruhan skor

Jumlah butir soal

Kategori skor:

$3,26-4,00=$ Sangat baik

$2,5^{1}-3,25=$ Baik

$1,76-2,50=$ Cukup Baik

1,Oo - 1,75 = Kurang Baik

Setelah data yang ada sudah terkumpul, teknik analisa data yang digunakan adalah deskriptif kualitatif. Teknik deskriptif kualitatif merupakan teknik analisis data dengan cara mengartikan data yang telah terkumpul berupa tabel, grafik, atau angka yang kemudian dijelaskan menjadi sebuah sistematis tentang suatu fenomena.

Langkah 5: Evaluasi, pada tahap kelima ini yakni merupakan tahapan terakhir dengan memberi ujicoba one to one kepada dua Guru Bahasa Inggris Sekolah Dasar. Hasil dari wawancara yang telah dilakukan dapat diperoleh kesimpulan bahwa setiap komponen yang dikembangkan dalam strategi pembelajaran yaitu (1) urutan pembelajaran, (2) kegiatan pembelajaran, (3) metode, (4) media, (5) evaluasi, dan (6) waktu sudah sesuai dan mudah untuk dipahami.

\section{Tabel 3 Penilaian Para Ahli}

\begin{tabular}{ll}
\hline Ahli & Nilai \\
\hline Materi & $77 \%$ (Baik) \\
Desain Pembelajaran & $\mathbf{7 2 \%}$ (Baik) \\
Media & $\mathbf{2 , 6 8}$ (Baik) \\
\hline
\end{tabular}

\section{SIMPULAN}

1. Strategi pembelajaran merupakan perencanaan yang berisi prosedur atau rangkaian kegiatan yang dirancang untuk mencapai tujuan pembelajaran yang diharapkan.
2. Strategi pembelajaran merupakan rencana tindakan yang sistematis dengan memanfaatkan metode dan berbagai sumber daya atau kekuatan dalam pembelajaran yang disusun untuk mencapai tujuan pembelajaran yang diterapkan.

3. Strategi pembelajaran meliputi komponenkomponen strategi pembelajaran yang meliputi urutan pembelajaran, kegiatan pembelajaran, metode, media, evaluasi, dan waktu.

\section{UCAPAN TERIMA KASIH}

Peneliti mengucapkan terima kasih kepada Ibu Dra. Suprayekti, M.Pd sebagai dosen pembimbing 1 yang telah meluangkan waktu untuk mebimbing peneliti dalam menyelesaikan penelititan ini. Peneliti juga mengucapakan terima kasih kepada Ibu Retno Widyaningrum, S.Kom, M.M sebagai dosen pembimbing 2 yang juga selalu memberikan masukan untuk penelitian pengembangan ini. Peneliti juga mengucapkan terimakasih kepada para ahli yang sudah menilai produk pengembangan ini, dan Sekolah Mardi Yuana yang telah mengizinkan peneliti melakukan peneliaitan pengembangan.

\section{DAFTAR PUSTAKA}

Anitah, Sri (2008). Strategi Pembelajaran di SD. Jakarta: Universitas Terbuka

Arsa, I Putu Suka (2015). Belajar dan Pembelajaran: Strategi Belajar Yang Menyenangkan. Media Akademi: Yogyakarta

Arsyad, Azhar (2011). Media Pembelajaran. Jakarta: PT Grafindo Perssada

Kasihani, K.E. (2008). English for Young Learners. Jakarta: PT Bumi Aksara

Kurniawan, Yudha (2004). Smart Games for Kids. Jakarta: PT WahyuMedia 
Mulyasa, E (2006). Menjadi Guru Profesional Menciptakan Pembelajaran Yang Kreatif dan Menyenangkan. Bandung: Rosda Karya

Pribadi, A. Beni (2009). Model Desain Sistem Pembelajaran. Jakarta: Dian Rakyati

Uno, Hamzah B. (2007). Model Pembelajaran: Menciptakan Proses Belajar Mengajar yang Kreatif dan Efektif. Jakarta: Bumi Aksara

Usman, Nurdin (2002). Konteks Implementasi Berbasis Kurikulum. Semarang: CV. Obor Pustaka 